\title{
PROTEÇÃO JURíDICA DO PATRIMÓNIO TURÍSTICO NO BRASIL
}

\author{
JOANDRE ANTONIO FERRAZ*
}

\begin{abstract}
RESUMO: A ordenação do património turístico é fundamental para o desenvolvimento planejado do setor. Essa ordenaçāo implica, principalmente, disciplinar o uso e ocupação do solo de interesse turístico. Disciplina da espécie compete, também, aos Estados. Este artigo indica conceitos, antecedentes, fundamentos jurídicos e cenário da atuação dos Estados na matéria.

UNITERMOS: Património turístico: ordenaçāo; solo de interesse turístico; uso e ocupação. Disciplina jurídica: atuação dos Estados.

ABSTRACT: The law' system of the tourism patrimony is fundarmental to the planned development of the sector. This law system involves, mainly, to discipline the use and occupation of areas with touristic intcrest. This kind of discipline is also due to the States. This article indicatcs concepts, antecedents, juridical principles and a vicw of the States action on the matter.
\end{abstract}

KEY WORDS: Touristic Patrimony: law system; areas of touristic interest; use and occupation. Juridical discipline: States action.

\section{CONCEITO}

Patrimônio turístico é uma expressāo que vem sendo utilizada pelo órgāo oficial de turismo de âmbito federal, a Embratur, desde os idos de 1975, para designar o conjunto de atrativos naturais e culturais que despertam o interesse de viajantes em conhecê-los. Nesse sentido, é matéria-prima necessária para a existência do ciclo econômico-turístico, a partir da qual, instalada a estrutura que permite a visitaçāo, é colocada como produto no mercado, de onde fundamenta-se a sua perenização. Por outro lado, à medida em que se incrementa a estrutura e, conseqüentemente, a visitaçāo, as características originais desse conjunto de atrativos sofre degradação ambiental, a ser, no mínimo, regulada e garantir tal peregrinaçāo.

(*) Mestre em Direito Económico pela Faculdade de Direito da Universidade de Sāo Paulo. Advogado de Entidades e Empresas de Turismo. Ex-Professor de "Legislação de Turismo“" em Cursos Superiores de Turismo.

End. para corresp.: Rua José Clemente, 255 - CEP 01428 - São Paulo - SP - Brasil. 
Vedar a visitação implica retirar o bem natural ou cultural do patrimônio turístico, crônico impasse entre os que defendem a preservação absoluta e os que propōem a preservação auto-sustentada desses bens. A regulação, por sua vez, acima de jurídica, há de fundamentarse em critérios técnicos definidores das formas não predatórias de utilização turística desse patrimônio, os quais apresentam-se em estágio pouco desenvolvido em nosso País.

Dados tais conceitos básicos, resta claro que a regulação por normas jurídicas do patrimônio turístico é do âmbito de estudo do Dircito Urbanístico e do Direito Econômico, ao impor limitaçōes de uso de bens que são transformados em produtos turísticos. Antes, porem, de atingir esses âmbitos, é objeto do Direito Constitucional, desde que tratado a nível de Constituição Federal, objeto específico deste artigo.

\section{ANTECEDENTES}

Os atrativos naturais e culturais de interesse turístico existentes no País são "cantados em prosa e verso", atingindo dimensão tal que, por muitos anos, não mereceram tratamento jurídico específico.

A necessidade de tratamento da espécie foi percebida com o fracasso na implantação do Projeto TURIS, patrocinado pela Embratur em 1973, visando ordenar o uso e ocupação da área litorânea localizada entre Rio de Janeiro e Santos. Concluído o projeto e definidas as respectivas normas de uso e ocupação, deparou-se a Embratur com a inexistência de regras jurídicas que amparassem sua aplicação de forma compulsória, causa de significativa descaracterização já ocorrida na área. Esta descaracterização provocada não só pelo particular, na ânsia de otimizar lucros imobiliários, mas também pelo próprio Poder Público, a exemplo de três praias que foram definitivamente aterradas quando das obras de construção da chamada Rodovia Rio-Santos (BR 101).

Esse cenário, que se projetava, então, como grande risco para o futuro do patrimônio turístico originou o projeto de lei voltado à sua proteção, convertido na Lei n. 6.513, de 20 de dezembro de 1977. Por essa lei instituiu-se um sistema de proteção das denominadas áreas especiais e dos locais de interesse turístico, assim definíveis em razão de bens naturais e culturais que ali existissem e devessem ser mantidos para permanência da motivação de visitá-los. Foi, portanto, o marco inicial da proteção jurídica do patrimônio turístico, ainda que, à época, o termo não fosse expressamente adotado na Constituição então vigente, outorgada pela Ementa n $^{\circ} 1$ de 1969.

\section{SITUAÇÃO CONSTITUCIONAL}

A Constituição Federal de 1988, diferentemente, não só adota a expressão patrimônio turístico em vários de seus dispositivos, como revela preocupação inédita com a questão do meio ambiente. De fato, dispōe o art. 24 da Lei Fundamental:

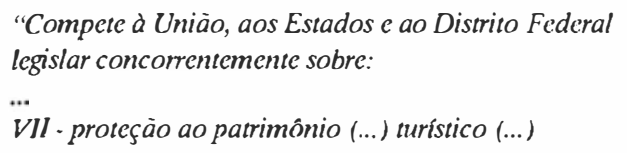

É fato, também, que em outro item do mesmo artigo, VIII, a Constituição utiliza expressão distinta, "bens e direitos de valor turístico", assim como em ambos os itens citados estejam, ao lado do turístico, o patrimônio, os bens e direitos de caráter histórico, cultural, artístico, estético e paisagístico. Desse modo, é fácil perceber que o aprendizado jurídico brasileiro sobre a matéria coloca em plano idêntico o que, em tese, seria gênero (turístico) e espécies (histórico, cultural, pasisagístico etc.), ao invés de limitar-se a indicar bens de valor natural e cultural como integrantes de um determinado patrimônio, no caso, o turístico. A própria Lei $n^{\circ} 6.513 / 77$, já citada, apesar de posterior ao uso da expressão pela Embratur, autora do projeto de lei que a precedeu, utiliza, como qualificativos dos bens que integram o patrimônio turístico, expressōes referentes à sua natureza, ou seja, turísticos, artísticos, arqueológicos etc.

Portanto, é ainda equívoco o conceito de patrimônio turístico no direito positivo brasileiro, que tende a ser melhor explicitado tecnicamente com o desenvolver de atividades concretas na área de sua proteção.

\section{COMPETENCIA}

Mostra a evolução das Constituiçōes Federais no Brasil que a competência para proteção do patrimônio turístico sempre foi comum dos três níveis de pessoas políticas: União, Estados e Municípios.

A Constituição de 1988, porém, foi a primeira a disciplinar, de forma expressa, sobre a competência para legislar a respeito dessa proteção, dando contorno mais operacional e menos programático à questão. Nesse sentido, o pré-transcrito art. 24, "caput”, estabelece competência concorrente para legislar sobre a matéria à União, Estados e Distrito Federal. E dispōem os parágrafos desse dispositivo constitucional: 
$\$ 1 .^{\circ}$ No âmbito da legislaçào concorrente, a compctênciada da Uniāo limitar-se- á a estabelecer normas gerais.

§2. A competência da Uniào para legislar sobre normas gerais nào exclui a competência suplementar dos Estados.

\$3. Inexistindo lei federal sobre normas gerais, os Estados exerceräo a competência legislativa plena, para atender a suas peculiaridades.

\$4. A superieniência de lei federal sobre normas gerais suspende a eficácia da le estadual, no que lhe for contrário.

A clareza desses parágrafos bem demonstra a importância legislativa que os Estados passaram a ter em matéria de proteção do patrimônio turístico, a qual, passados mais de três anos, têm sido pouco explorada. Tal importância merece tópico próprio no presente artigo, com o objetivo de destacar a questāo e, eventualmente, despertar a consciência de técnicos e políticos para o enorme espaço aberto aos Estados para atuarem concretamente no planejamento turístico.

\section{ATUAÇÃO DOS ESTADOS}

A competência legislativa estadual tem sido tradicionalmente escassa desde a Constituição Federal de 1934, de um lado em razão do modelo concentrador na Uniāo da maior parte dos poderes políticos, e, de outro, pelo crescimento dos Municípios, que ocasionou o incremento legislativo de seu peculiar interesse. Talvez por isto, a competência legislativa expressa que os Estados passaram a ter na matéria sob exame não venha sendo, com honrosas exceções, exercitada pelos mesmos, ampliando os riscos de degradação dos bens que integram o patrimônio turístico. Que seja de nosso conhecimento, apenas o Estado do Ceará vem, há alguns anos, atuando no planejamento físicoturístico de sua orla marítima e usando dessa competência, fundado em estudos técnicos consistentes.

O Estado de São Paulo, por exemplo, conta com ato regulamentar do gênero desde a década de 1970, se, no entanto, qualquer fundamentação técnico-urbanística ou jurídica que lhe permita aplicá-lo. Enquanto isto, assiste-se à crescente ação predatória de seus atrativos naturais, heroicamente defendidos, às vezes, por entidades privadas que, por sua vez, esbarram na inexistência de normas adequadas para sustentar suas teses.

Aqui e acolá sabe-se de tentativas de regulação do uso e ocupação do solo de interesse turístico, como na Paraíba, Pernambuco, Alagoas e Bahia, porém de forma tímida e, quase sempre, localizadas, sem in tegração em um programa mais amplo.
Parece que a maioria dos Estados permanece no aguardo, uma vez mais, de que a Embratur, combalida em sua estrutura, exerça a competência que lhe assegura a antes indicada Lei $n^{\circ} 6.513 / 77$, para o que nunca possuiu (menos ainda nos dias atuais) recursos materias e humanos proporcionais à dimensāo da empreitada. Esquecem, inclusive, que essa lei lhes confere, também, poderes para atuarem como agentes de proteção do patrimônio turístico, mesmo antes das novas disposiçōes constituicionais pré-comentadas, poderes esses também pouco utilizados nestes dez anos em que a citada lei está regulamentada.

E dúvida inexiste quanto a ser essa ação de natureza pública, sem embargo do necessário apoio da comunidade, que, aliás, vem tentando, sozinha, conter ao menos as agressões mais aparentes que sofre o patrimônio turístico.

Essa inércia da maior parte dos Estados não encontra, assim, justificativa jurídica para continuar ocorrendo, e, nem técnica, pois os meios acadêmicos aí estāo para oferecer subsídios técnicos a respeito, se chamados a tanto. O certo é que, se quiserem, os Estados detêm, hoje, competência legislativa para regularem o uso e a ocupação do patrimônio físico-turístico existente em seus territórios, restando, como de hábito, que tenham vontade política de fazê-lo.

$\mathrm{O}$ fato de as experiências em andamento serem de iniciativa dos Estados no Nordeste revela que, apesar de menos descaracterizados em seus atrativos naturais que os do Sudeste e Sul, em virtude do menor grau de industrialização, a sensibilidade política daqueles em torno da matéria é muito maior do que a desses. Isto apesar de os Estados do Sudeste e do Sul terem atingido nível de desenvolvimento econômico que deveria lhes impor a obrigação de melhorar o padrão de qualidade de vida em seus territórios, de seus habitantes e visitantes.

\section{CONCLUSÕES}

Ilusório entender que os atrativos naturais e culturais que integram o património turístico brasileiro são de tal monta que sempre existirāo. A ação devastadora do homem é mais rápida do que a capacidade de renovação desses atrativos, pondo em risco a inegável vocação turística do País. É ingênuo buscar, por outro lado, defender esse patrimônio transformando-o em santuário vedado à presença humana, pois o País carece de alternativas para o desenvolvimento, entre as quais o turismo poderá ser das mais relevantes.

Enquanto nos Estados Unidos um deserto como Las Vegas e um pântano como a Flórida foram convertidos em pólos turísticos artificais de atratividade mundial, vê-se o definhamento dos atrativos natu- 
rais brasileiros. Nāo porque, como comentado, falte instrumentaçāo jurídica. Nāo porque, acredita-se, falte conhecimento técnico. Mas, certamente, por ausência de vontade política, que nāo pode se exaurir com a realizaçāo da ECO-92.

E essa vontade nāo depende só da Uniāo. Todos os Estados e, também, os Municípios possuem instrumentos para concretizá-la, se a tiverem, ou se forem pressionados a tanto. Caso contrário, uma vez mais, ter-se-á à māo, dispositivos constitucionais e legais de cunho meramente programáticos, ou seja, verdadeiras letras mortas.

\section{BIBLIOGRAFIA}

1. BRASIL, Constituição. Constituição da República Federativa do Brasil, de 05 de outubro de 1988. São Paulo, Atlas, 1989. 200p.

2. FERRAZ, J. A. Ordenação jurídica do turismo. São Paulo, FD/USP, 1983. 332p. (Dissertação de Mestrado).

3. EMBRATUR. Turis - Desenvolvimento turístico do litoral Rio-Santos. Embratur/Ministério da Indústria e do Comércio, 1975, 113 p. 